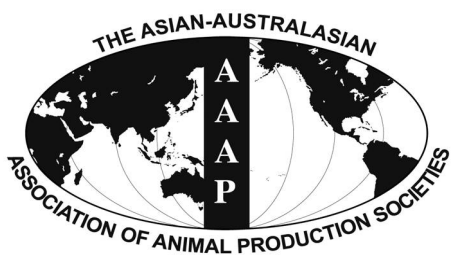

Open Access

Asian Australas. J. Anim. Sci.

Vol. 29, No. 9 : 1280-1286 September 2016

http://dx.doi.org/10.5713/ajas.16.0053

Www.ajas.info

pISSN 1011-2367 elSSN 1976-5517

\title{
Effects of Medicinal Herb Extracts on In vitro Ruminal Methanogenesis, Microbe Diversity and Fermentation System
}

\author{
Eun Tae Kim ${ }^{\text {a }}$, Hee Soon Hwang ${ }^{1, a}$, Sang Min Lee ${ }^{2}$, Shin Ja Lee ${ }^{1}$, Il Dong Lee ${ }^{1}$, Su Kyoung Lee ${ }^{1}$, \\ Da Som Oh ${ }^{1}$, Jung Hwa Lim ${ }^{1}$, Ho Baek Yoon, Ha Yeon Jeong, Seok Ki Im, and Sung Sill Lee ${ }^{1, *}$ \\ National Institute of Animal Science, RDA, Cheonan 31000, Korea
}

\begin{abstract}
This study was aimed to evaluate the in vitro effects of medicinal herb extracts (MHEs) on ruminal fermentation characteristics and the inhibition of protozoa to reduce methane production in the rumen. A fistulated Hanwoo was used as a donor of rumen fluid. The MHEs (T1, Veratrum patulum; T2, Iris ensata var. spontanea; T3, Arisaema ringens; T4, Carduus crispus; T5, Pueraria thunbergiana) were added to the in vitro fermentation bottles containing the rumen fluid and medium. Total volatile fatty acid (tVFA), total gas production, gas profiles, and the ruminal microbe communities were measured. The tVFA concentration was increased or decreased as compared to the control, and there was a significant $(\mathrm{p}<0.05)$ difference after $24 \mathrm{~h}$ incubation. $\mathrm{pH}$ and ruminal disappearance of dry matter did not show significant difference. As the in vitro ruminal fermentation progressed, total gas production in added MHEs was increased, while the methane production was decreased compared to the control. In particular, Arisaema ringens extract led to decrease methane production by more than $43 \%$. In addition, the result of real-time polymerase chain reaction indicted that the protozoa population in all added MHEs decreased more than that of the control. In conclusion, the results of this study indicated that MHEs could have properties that decrease ruminal methanogenesis by inhibiting protozoa species and might be promising feed additives for ruminants. (Key Words: Medicinal Herb Extracts, Methane Production, Protozoa, Rumen Fermentation)
\end{abstract}

\section{INTRODUCTION}

Research focused on decreasing enteric methane production from ruminants has been reported in the last decade, with various mitigation strategies available to the livestock fields (Knapp et al., 2014). Enteric methane production from ruminal fermentation of feeds accounts for approximately $30 \%$ of the total anthropogenic methane (FAO, 2006). Methane production from ruminants is a serious contributor to global warming as well as an economic loss to the farmer with the loss of $2 \%$ to $15 \%$ of the gross energy intake through their unique digestive

\footnotetext{
* Corresponding Author: Sung Sill Lee. Tel: +82-55-772-1883, Fax: +82-55-772-1889, E-mail: 1ss@gnu.ac.kr

${ }^{1}$ Division of Applied Life Science (BK21 $1^{+}$, IALS), Gyeongsang National University, Jinju 52828, Korea.

${ }^{2}$ Easy Bio, Inc., Seoul 06253, Korea.

${ }^{a}$ These authors contributed equally to the work.

Submitted Jan. 18, 2016; Revised Feb. 23, 2016; Accepted Mar. 19, 2016
}

process (Johnson and Johnson, 1995; Ellis et al., 2007). Rumen nutritionists have found bio-active materials for reducing methane production without an adverse effect on ruminal fermentation. Natural sources including plant extracts and essential oils and marine algae have been studied and screened as additives for ruminants feeds (Dubois et al., 2013; Durmic et al., 2014), but only a few substances have been shown to have an effect on ruminal methane production. Plant extracts such as condensed tannin, saponins and essential oils modify the ruminal ecosystem by suppressing ruminal protozoa, and inhibiting bacteria and archaea (Tan et al., 2011; Patra and Yu, 2012). According to above studies, research on the symbiosis of protozoa with methanogens in the rumen is well reported, and the inhibition of protozoa has been shown to be an effective approach to decrease ruminal methane production. However, there are limited studies about the effect of medicinal herb extracts (MHEs) on ruminal methanogenesis.

This study was aimed to evaluate the effect of MHEs on 
the in vitro ruminal methane production, fermentation characteristics and how some plants secondary metabolites might act as inhibitors of protozoa closely related with methanogens in the rumen.

\section{MATERIALS AND METHODS}

\section{Preparation of medical herb extracts}

MHEs were obtained from Plant Extract Bank at the Korea Research Institute of Bioscience and Biotechnology (Daejeon, Korea). Plants were collected from fields in Korea (Table 1). Each plant was cut into small pieces and dried naturally under shade. The dried plants (100 g) were extracted with $99.9 \%$ methyl alcohol (1 L) using ultrasonic cleaner (Branson Ultrasonics corporation, Danbury, CT, USA) at room temperature for 3 days. After extraction, the solutions were filtered and the solvents were evaporated under vacuum. Stock solutions $(20 \mathrm{mg} / \mathrm{mL})$ of the extract were dissolved in dimethyl sulfoxide (Sigma-Aldrich Chemical Co., St. Louis, Mo, USA) and diluted using culture media immediately before experiments.

\section{Ruminal inoculum and in vitro incubation}

A fistulated Hanwoo cow (three years old) of $450 \mathrm{~kg}$ body weight was used as the donor of rumen fluid. Timothy and commercial concentrate in the ratio of 60:40 were fed at $3 \%$ of body weight twice a day (09:00 and 17:00). Water and mineral-vitamin block were allowed ad libitum. The rumen fluid was collected from the fistulated Hanwoo before morning feeding. Rumen liquor was filtered through four layers of cheesecloth before mixing with buffer and was maintained at $39^{\circ} \mathrm{C}$. The $15 \mathrm{~mL}$ of rumen fluid-buffer mixture, comprising McDougall buffer (McDougall, 1948) and rumen liquor in the ratio of 2 to 1 , was dispensed anaerobically into $50 \mathrm{~mL}$ serum bottles containing $0.3 \mathrm{~g}$ of timothy substrate and MHEs (5\% of substrate). The serum bottles were filled with $\mathrm{O}_{2}$-free $\mathrm{N}_{2}$ gas capped with a rubber stopper and held in a shaking incubator (Jeio Tech, SI-900R, Daejeon, Korea; $120 \times \mathrm{rpm})$ at $39^{\circ} \mathrm{C}$ for $12 \mathrm{~h}, 24 \mathrm{~h}$, and $48 \mathrm{~h}$ incubations. The in vitro experiment was evaluated in triplicate runs for data analysis using 54 serum bottles (6 treatments $\times 3$ incubation times $\times 3$ replication) with a completely randomized design.
Gas production measurement, analysis of gas and ruminal fermentation profiles

At the end of incubation, total gas production was measured according to the assay outlined by Theodorou et al. (1994). A detachable pressure transducer and a digital readout voltmeter (Laurel Electronics, Inc., Costa Mesa, CA, USA) were used to measure the headspace gas pressure of fermenting cultures. For the total gas production measurement, the transducer was modified in a way that it could be linked to the inlet of a disposable Luer-lock threeway stopcock (Theodorou et al., 1994). Gas pressure in the headspace was read from the display unit after insertion of the hypodermic syringe needle through the butyl rubber stopper above the culture medium. The headspace gas in the serum bottle was collected for analyzing methane, carbon dioxide and hydrogen by gas chromatography (Agilent Technologies HP 5890, Santa Clara, CA, USA) conducted using a TCD detector with a Column Carboxen 1006PLOT capillary column $30 \mathrm{~m} \times 0.53 \mathrm{~mm}$ (Supelco, Bellefonte, PA, USA). The culture was subsampled for the analysis of $\mathrm{pH}$ (Mettler-Toledo, MP230, Greifensee, Switzerland), volatile fatty acid (VFA) concentration and genomic DNA extraction. The VFA analysis was performed with a high performance liquid chromatography (Agilent-1200, Waldbronn, Germany) equipped with column (300 $\mathrm{mm} \times 7.8$ mm I.d. MetaCarb 87H, Varian, Palo Alto, CA, USA). In vitro dry matter disappearance rate was estimated by the modified method of nylon bag digestion process. Briefly, after incubation, the nylon bag with substrate was washed twice in a water-bath equipped with Heidolphs Rotamax 120 (Heidolph Instrument, Nuremberg, Germany) at $100 \times \mathrm{rpm}$ for $30 \mathrm{~min}$. Washed nylon bags were then dried to a constant weight at $60^{\circ} \mathrm{C}$. Dry matter disappearance was determined by weight difference before and after incubation in the serum bottle.

\section{Microbial growth rate}

Incubated samples taken from each fermentation period were centrifuged at $3,000 \times \mathrm{rpm}$ for $3 \mathrm{~min}$ to remove feed particles, and the supernatants were re-centrifuged at $14,000 \times \mathrm{rpm}$ for $3 \mathrm{~min}$ to settle the pellets down. After that, sodium phosphate buffer ( $\mathrm{pH}$ 6.5) was added to these precipitates and vortexed. Growth rates of total microbes were estimated as optical density values using spectrophotometer (Model 680, Bio-Rad Laboratories,

Table 1. Technical information regarding medicinal herb extracts used in this study

\begin{tabular}{llll}
\hline Stock No. & \multicolumn{1}{c}{ Scientific name } & Family & Sampling period \\
\hline $004-034$ & Veratrum patulum & Liliaceae & May 11, 2001 \\
$012-017$ & Iris ensata var. spontanea & Iridaceae & September 9, 2001 \\
$019-088$ & Arisaema ringens & Araceae & October 11, 2002 \\
$028-080$ & Carduus crispus & Compositae & May 18, 2005 \\
$036-088$ & Pueraria thunbergiana & Leguminosae & August 6, 2009 \\
\hline
\end{tabular}

Medical herb extracts were obtained from Plant Extract Bank (PEB) at Korea Research Institute of Bioscience and Biotechnology (Daejeon, Korea). 
Hercules, CA, USA) at $550 \mathrm{~nm}$.

\section{Quantitative polymerase chain reaction assays}

DNA extraction: A high-speed reciprocal shaker which retains samples in screw-capped tubes containing silica beads was used for DNA extraction. Total nucleic acid was extracted from the incubated rumen samples by using the modified bead-beating protocol with the Soil kit (Macherey-nagel, Düren, Germany). Briefly $1.0 \mathrm{~mL}$ aliquot was taken from the incubated culture solution and was centrifuged at 3,000×rpm. Nucleic acid concentrations were measured by using a NanoDrop Spectrophotometer (Thermo Scientific, Wilmington, DE, USA).

Polymerase chain reaction primers: The polymerase chain reaction (PCR) primer sets used in this study for amplification of ciliate protozoa (Forward primer: GAG CTA ATA CAT GCT AAG GC, Reverse primer: CCC TCA CTA CAA TCG AGA TTT AAG G), Fibrobacter succinogenes (Forward primer: GTT CGG AAT TAC TGG GCG TAA A, Reverse primer: CGC CTG CCC CTG AAC TAT C), Ruminococcus flavefaciens (Forward primer: CGA ACG GAG ATA ATT TGA GTT TAC TTA GG, Reverse primer: CGG TCT CTG TAT GTT ATG AGG TAT TAC C) and Ruminococcus albus (Forward primer: CCC TAA AAG CAG TCT TAG TTC G, Reverse primer: CCT CCT TGC GGT TAG AAC A) were the same as those referenced by Skillman et al. (2006), Denman and McSweeney (2006) and Koike and Kobayashi (2001), respectively. Total bacteria primer set (Forward-CGGCAACGAGCG CAACCC, Reverse-CCATTGTAGCACGTGTGTAGCC) was used as the internal standard (Demman and McSweeney, 2006).

Real-time PCR: Real-time PCR (RT-PCR) assays for enumeration of microbes were performed according to the methods described by Denman and McSweeney (2006) and Denman et al. (2007) on a real-time PCR Machine (CFX96 Real-Time system, BIO RAD, Hercules, CA, USA) using the SYBR Green Supermix (QPK-201, Toyobo Co., LTD., Tokyo, Japan). The values of cycle threshold (Ct) after PCR reactions were used to determine fold change (number of fold difference) of different microbial population relative to control without additives. Abundance of these microbes was expressed by the equation:

\section{Relative quantification $=2^{-\Delta \mathrm{Ct}(\text { Target })-\Delta \mathrm{Ct}(\text { Control })}$}

Where, Ct represents threshold cycle. All RT-PCR reaction mixtures (final volume of $20 \mu \mathrm{L}$ ) contained forward and reverse primers, the SYBR Green Supermix and DNA template. A negative control without the template DNA was used in every RT-PCR assay for each primer. The RT-PCR amplification of the target DNA, included the annealing and the extension temperature, was performed as previously described (Koike and Kobayashi, 2001; Denman and McSweeney, 2006; Skillman et al., 2006).

\section{Statistical analysis}

Data were analyzed using the general linear model procedure of the Statistical Analysis System Institute, Inc. (SAS Institute, 1996). The effects of MHEs on pH, VFA, dry matter degradability, total gas production, gas profiles and microbial growth were compared to the controls and significant differences between treatment means were examined using Duncan's multiple comparison tests. A $p<0.05$ was considered to be statistically significant.

\section{RESULTS AND DISCUSSION}

The in vitro ruminal fermentation characteristics are shown in Table 2. The $\mathrm{pH}$ of culture solution did not show a significant difference between control and treatments $(\mathrm{p}<0.05)$. Dry matter degradability was not significantly different, but numerically higher compared with the control. The total volatile fatty acid (tVFA) concentrations were decreased or increased by addition of MHEs at $12 \mathrm{~h}$ incubation, while they were significantly increased $(p<0.05)$ compared to the control at $24 \mathrm{~h}$ incubation except Veratrum patulum. The acetate:propionate $(\mathrm{C} 2: \mathrm{C} 3)$ ratio was lowered by the addition of all MHEs compared to the control at $24 \mathrm{~h}$ incubation. The effects of MHEs on total gas production and gas profiles are presented in Table 3. Total gas production was higher than that of the control. There was significant difference $(\mathrm{p}<0.05)$ at $48 \mathrm{~h}$ incubation. MHEs decreased the in vitro methane production at $12 \mathrm{~h}$ and $24 \mathrm{~h}$ incubation. In particular, Iris ensata var. spontanea and Arisaema ringens extracts significantly reduced $(\mathrm{p}<0.05)$ the in vitro methane production by $39.6 \%$ after $12 \mathrm{~h}$ incubation and $43.9 \%$ after $24 \mathrm{~h}$ incubation, respectively. Carbon dioxide production was not significantly different. Unfortunately, hydrogen was not detected in this in vitro study. According to the study of Janssen (2010), it is difficult to accumulate hydrogen in the ruminal ecosystem. The normally low concentration is accounted for by the utilization of hydrogen by ruminal methanogens. Carroll and Hungate (1955) also reported that hydrogen was metabolized quickly, with stoichiometric methane production when added to in vitro ruminal fermentation. Some researchers reported the rate of methane production and the concentrations of dissolved hydrogen instead of hydrogen as an intermediate in rumen fermentation (Hungate, 1967; Barry et al., 1977; Hillman et al., 1985). In addition, Vogels et al. (1980) reported that hydrogen production is closely related with anaerobic ciliates. The growth of the rumen microbes as affected by all treatments is presented in Table 4. The result of microbial growth rate was not significant difference between the control and 
Table 2. Effects of medicinal herb extracts on ruminal fermentation characteristics according to incubation time

\begin{tabular}{|c|c|c|c|c|c|c|c|}
\hline \multirow{2}{*}{ Item } & \multirow{2}{*}{ Control $^{1}$} & \multicolumn{5}{|c|}{ Treatments $^{1}$} & \multirow{2}{*}{ SEM } \\
\hline & & T1 & $\mathrm{T} 2$ & T3 & $\mathrm{T} 4$ & T5 & \\
\hline & ----------- & -------- & ----- & ------- & ------- & ------ & \\
\hline DMD (\%) & 27.64 & 27.54 & 25.00 & 27.58 & 26.48 & 27.72 & 1.70 \\
\hline $\mathrm{pH}$ & 6.61 & 6.62 & 6.63 & 6.63 & 6.65 & 6.62 & 0.03 \\
\hline tVFA (mM) & 40.56 & 45.42 & 38.87 & 45.11 & 39.87 & 47.04 & 4.98 \\
\hline Acetate (mM) & 31.77 & 33.10 & 31.36 & 33.17 & 33.08 & 33.45 & 1.55 \\
\hline Propionate (mM) & 16.32 & 19.28 & 16.87 & 16.68 & 19.98 & 20.97 & 4.13 \\
\hline $\mathrm{C} 2: \mathrm{C} 3$ ratio & 1.96 & 1.73 & 1.91 & 1.99 & 1.75 & 1.71 & 0.36 \\
\hline DMD (\%) & 36.67 & 36.99 & 36.44 & 34.70 & 35.45 & 38.04 & 2.08 \\
\hline $\mathrm{pH}$ & $6.16^{\mathrm{ab}}$ & $6.16^{\mathrm{b}}$ & $6.16^{\mathrm{b}}$ & $6.27^{\mathrm{a}}$ & $6.23^{\mathrm{ab}}$ & $6.26^{\mathrm{a}}$ & 0.05 \\
\hline tVFA (mM) & $45.62^{\mathrm{c}}$ & $41.22^{\mathrm{c}}$ & $62.57^{\mathrm{b}}$ & $59.47^{\mathrm{b}}$ & $86.21^{\mathrm{a}}$ & $83.52^{\mathrm{a}}$ & 4.87 \\
\hline Acetate $(\mathrm{mM})$ & $39.92^{\mathrm{b}}$ & $36.71^{\mathrm{b}}$ & $39.92^{\mathrm{b}}$ & $36.71^{\mathrm{b}}$ & $54.04^{\mathrm{a}}$ & $53.01^{\mathrm{a}}$ & 2.16 \\
\hline Propionate (mM) & $22.65^{\mathrm{b}}$ & $25.11^{\mathrm{b}}$ & $24.32^{\mathrm{b}}$ & $22.76^{\mathrm{b}}$ & $31.71^{\mathrm{a}}$ & $30.34^{\mathrm{a}}$ & 1.86 \\
\hline $\mathrm{C} 2: \mathrm{C} 3$ ratio & $1.77^{\mathrm{a}}$ & $1.48^{\mathrm{b}}$ & $1.64^{\mathrm{ab}}$ & $1.62^{\mathrm{ab}}$ & $1.70^{\mathrm{a}}$ & $1.75^{\mathrm{a}}$ & 0.12 \\
\hline DMD (\%) & 44.11 & 47.34 & 44.92 & 45.89 & 45.88 & 47.15 & 1.67 \\
\hline $\mathrm{pH}$ & 5.95 & 5.98 & 5.97 & 5.99 & 5.96 & 5.98 & 0.03 \\
\hline $\operatorname{tVFA}(\mathrm{mM})$ & $99.57^{\mathrm{ab}}$ & $101.28^{\mathrm{ab}}$ & $104.40^{\mathrm{a}}$ & $99.60^{\mathrm{ab}}$ & $97.57^{\mathrm{b}}$ & $97.74^{\mathrm{b}}$ & 2.50 \\
\hline Acetate $(\mathrm{mM})$ & $65.66^{\mathrm{b}}$ & $66.37^{\mathrm{ab}}$ & $68.27^{\mathrm{a}}$ & $66.42^{\mathrm{ab}}$ & $64.95^{\mathrm{b}}$ & $64.93^{\mathrm{b}}$ & 1.09 \\
\hline Propionate (mM) & 33.91 & 33.20 & 33.97 & 32.94 & 33.31 & 33.08 & 0.57 \\
\hline $\mathrm{C} 2: \mathrm{C} 3$ ratio & $1.94^{\mathrm{d}}$ & $2.00^{\mathrm{abc}}$ & $2.01^{\mathrm{ab}}$ & $2.02^{\mathrm{a}}$ & $1.95^{\mathrm{cd}}$ & $1.96^{\mathrm{bcd}}$ & 0.03 \\
\hline
\end{tabular}

SEM: standard error of the mean; DMD, dry matter degradability; tVFA, total volatile fatty acid.

${ }^{1}$ Control, no addition; T1, Veratrum patulum; T2, Iris ensata var. spontanea; T3, Arisaema ringens; T4, Carduus crispus; T5, Pueraria thunbergiana.

${ }^{\mathrm{a}-\mathrm{d}}$ Means in the same row with different superscripts differ significantly $(\mathrm{p}<0.05)$.

treatments. The effect of MHEs on ruminal microbe and saponins inhibited ruminal protozoa diversity, and the diversities at $24 \mathrm{~h}$ incubation is shown in Figure 1. The reduced methane production might be related with a protozoa population in all added MHEs was shown to decreased protozoa population (Makkar et al., 1995; Hristov decrease dramatically $(\mathrm{p}<0.05)$ as compared with the et al., 2003). This finding agreed with the present results control (Figure 1a). From the study of Eom et al. (2013), that Iris ensata var. spontanea extract led to reduce ruminal plants of Iridaceae in Korea contain tannin and various methane production by $39.6 \%$ and $34.8 \%$ at $12 \mathrm{~h}$ and $24 \mathrm{~h}$ kinds of terpenoids. According to previous studies, tannins incubations, respectively. Among MHEs treatments,

Table 3. Effects of medicinal herb extracts on gas production and gas profiles according to incubation time

\begin{tabular}{|c|c|c|c|c|c|c|c|}
\hline \multirow{2}{*}{$\begin{array}{l}\text { Item } \\
(\mathrm{mL} / \mathrm{g} \mathrm{DM})\end{array}$} & \multirow{2}{*}{ Control $^{1}$} & \multicolumn{5}{|c|}{ Treatments $^{1}$} & \multirow{2}{*}{ SEM } \\
\hline & & $\mathrm{T} 1$ & $\mathrm{~T} 2$ & T3 & $\mathrm{T} 4$ & T5 & \\
\hline Gas & $187.63^{\mathrm{b}}$ & $193.23^{\mathrm{a}}$ & $172.16^{\mathrm{cd}}$ & $177.13^{\mathrm{c}}$ & $171.05^{\mathrm{d}}$ & $176.39^{\mathrm{cd}}$ & 3.04 \\
\hline $\mathrm{CH}_{4}$ & $5.46^{\mathrm{a}}$ & $5.08^{\mathrm{ab}}$ & $3.30^{\mathrm{b}}$ & $3.53^{\mathrm{b}}$ & $4.38^{\mathrm{ab}}$ & $4.61^{\mathrm{ab}}$ & 0.92 \\
\hline $\mathrm{CO}_{2}$ & 64.87 & 75.26 & 61.19 & 66.90 & 61.20 & 71.74 & 8.53 \\
\hline Gas & $237.05^{\mathrm{b}}$ & $245.77^{\mathrm{a}}$ & $244.24^{\mathrm{ab}}$ & $239.86^{\mathrm{ab}}$ & $240.28^{\mathrm{ab}}$ & $241.97^{\mathrm{ab}}$ & 4.13 \\
\hline $\mathrm{CH}_{4}$ & $15.27^{\mathrm{a}}$ & $11.70^{\mathrm{ab}}$ & $9.96^{\mathrm{ab}}$ & $8.57^{\mathrm{b}}$ & $10.14^{\mathrm{ab}}$ & $15.20^{\mathrm{a}}$ & 3.35 \\
\hline $\mathrm{CO}_{2}$ & 97.67 & 109.91 & 104.7 & 98.01 & 109.66 & 126.30 & 15.26 \\
\hline Gas & $265.83^{b}$ & $280.30^{\mathrm{a}}$ & $280.56^{\mathrm{a}}$ & $278.08^{\mathrm{a}}$ & $279.51^{\mathrm{a}}$ & $276.81^{\mathrm{a}}$ & 2.85 \\
\hline $\mathrm{CH}_{4}$ & $32.36^{\mathrm{ab}}$ & $36.93^{\mathrm{a}}$ & $28.49^{\mathrm{b}}$ & $26.48^{\mathrm{b}}$ & $33.04^{\mathrm{b}}$ & $32.58^{\mathrm{ab}}$ & 3.32 \\
\hline $\mathrm{CO}_{2}$ & $135.30^{\mathrm{ab}}$ & $148.46^{\mathrm{a}}$ & $113.66^{\mathrm{b}}$ & $135.00^{\mathrm{ab}}$ & $127.54^{\mathrm{ab}}$ & $140.35^{\mathrm{ab}}$ & 13.58 \\
\hline
\end{tabular}

SEM: standard error of the mean.

${ }^{1}$ Control, no addition; T1, Veratrum patulum; T2, Iris ensata var. spontanea; T3, Arisaema ringens; T4, Carduus crispus; T5, Pueraria thunbergiana.

${ }^{\mathrm{a}-\mathrm{d}}$ Means in the same row with different superscripts differ significantly $(\mathrm{p}<0.05)$. 
Table 4. Effects of medicinal herb extracts on growth rate of ruminal microbes according to incubation time

\begin{tabular}{llcccccc}
\hline \multirow{2}{*}{$\begin{array}{c}\text { Incubation } \\
\text { time (h) }\end{array}$} & Control $^{1}$ & \multicolumn{6}{c}{ Treatments $^{1}$} \\
\cline { 3 - 8 } & & $\mathrm{T} 1$ & $\mathrm{~T} 2$ & $\mathrm{~T} 3$ & $\mathrm{~T} 4$ & $\mathrm{~T} 5$ & \\
\hline 12 & $0.45^{\mathrm{abc}}$ & $0.42^{\mathrm{c}}$ & $0.43^{\mathrm{bc}}$ & $0.50^{\mathrm{ab}}$ & $0.51^{\mathrm{a}}$ & $0.52^{\mathrm{a}}$ & 0.04 \\
24 & 0.40 & 0.40 & 0.39 & 0.40 & 0.37 & 0.39 & 0.03 \\
48 & $0.42^{\mathrm{ab}}$ & $0.44^{\mathrm{a}}$ & $0.45^{\mathrm{a}}$ & $0.44^{\mathrm{a}}$ & $0.35^{\mathrm{b}}$ & $0.48^{\mathrm{a}}$ & 0.04 \\
\hline
\end{tabular}

SEM, standard error of the mean.

${ }^{1}$ Control, no addition; T1, Veratrum patulum; T2, Iris ensata var. spontanea; T3, Arisaema ringens; T4, Carduus crispus; T5, Pueraria thunbergiana.

${ }^{a-c}$ Means in the same row with different superscripts differ significantly $(\mathrm{p}<0.05)$.

Arisaema ringens and Pueraria thunbergiana, and Carduus crispus used in this study are known to have saponin and flavonoid properties (Kim and Kim, 2003; Lee et al., 2009; Kim et al., 2012). The addition of Arisaema ringens, Pueraria thunbergiana, and Carduus crispus led to decrease the protozoa population in this study. Patra and Saxena (2010) showed that saponins might decrease the ruminal methanogenesis by inhibiting rumen protozoa or

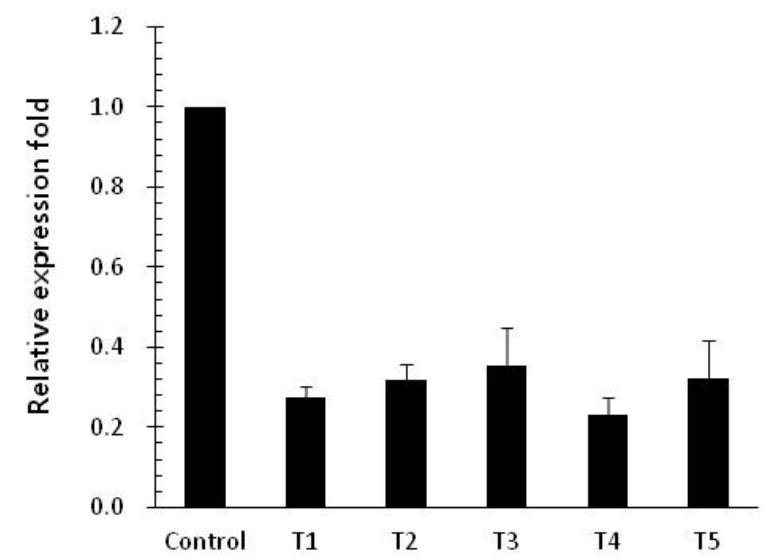

(a) Ciliate protozoa

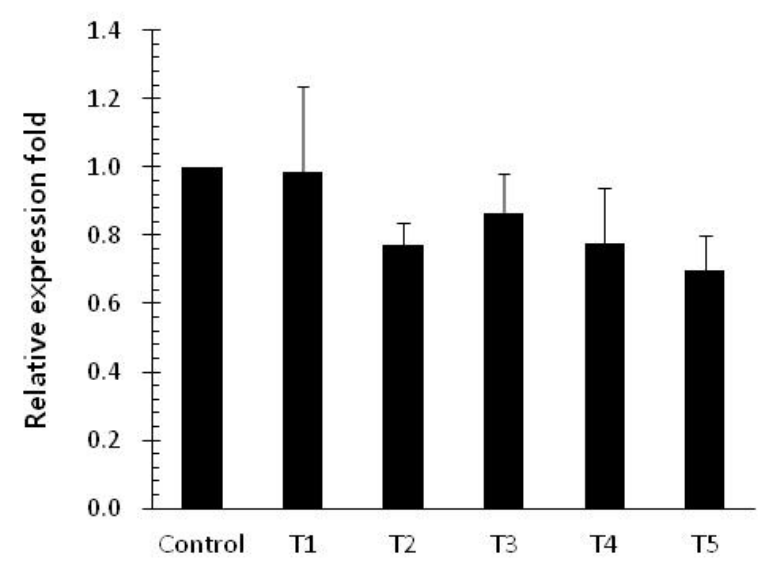

(c) Ruminococcus flavefaciens the numbers and activity of methanogens with high dosage of saponins although the direct effect of saponins on methanogens has not been reported clearly. Oskoueian et al. (2013) reported that flavonoids inhibited the total protozoa and total methanogens, and decreased ruminal methane production. In addition, the dry matter degradability and other ruminal fermentation characteristics were not affected by flavanoids. Furthermore, the diversities of Fibrobacter succinogenes, Ruminococcus flavefaciens, and Ruminococcus albus considered representative cellulolytic bacterial species in the rumen are shown in Figure 1 (b, c, and d). The F. succinogenes community under MHEs except for Carduus crispus was shown to increase, while the $R$. flavefaciens and $R$. albus diversities under all MHEs decreased as compared with the control. In particular, $F$. succinogenes has been known as an important species for fiber digestion in the rumen. Minato and Suto (1978) showed that $F$. succinogenes had the highest cellulose attachment ability among ruminal bacteria in vitro. $R$. flavefaciens and $R$. albus are known as promising bacteria to produce succinic acid and hydrogen, respectively

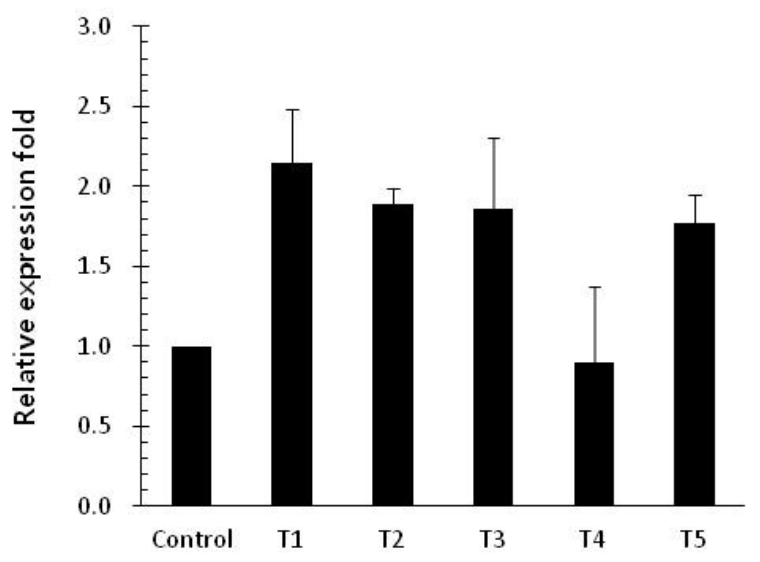

(b) Fibrobacter succinogenes

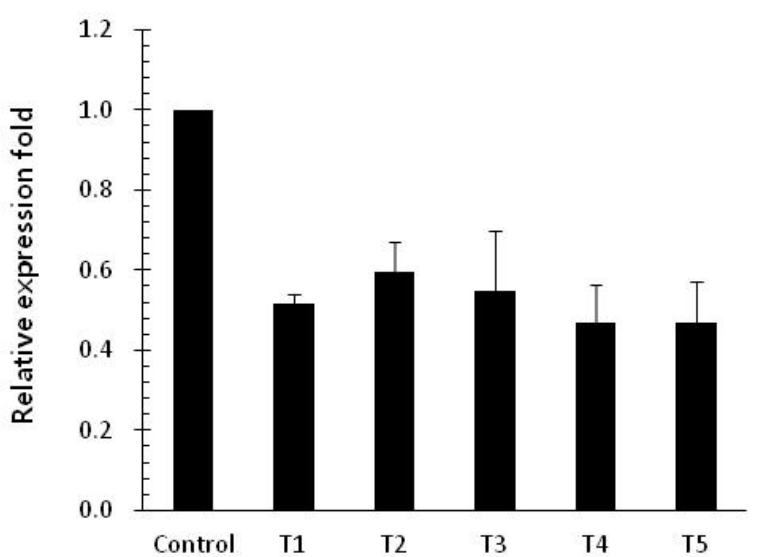

(d) Ruminococcus albus

Figure 1. Relative quantification analysis of microbial populations in vitro ruminal fermentation by the addition of different medical herb extracts at $24 \mathrm{~h}$ incubation (Control, no addition; T1, Veratrum patulum; T2, Iris ensata var. spontanea; T3, Arisaema ringens; T4, Carduus crispus; T5, Pueraria thunbergiana). 
(Latham and Wollin, 1977; Ntaikou et al., 2008). This finding agreed that the decreased $R$. flavefaciens and $R$. albus populations might be related with the increased propionate and undetected hydrogen production in this study. Moreover, hydrogen produced during enteric fermentation in ruminants is the critical concern to the microbial ecosystem and the regulation of hydrogen is the key to decrease methane production from ruminal fermentation (Hungate, 1967). In addition, the formation of propionate from succinate would affect the lower availability of hydrogen for the ruminal methanogenesis (Mitsumori and Sun, 2008).

In conclusion, this study of screening a variety of native plant extracts including MHEs may provide useful information on the potential candidates for ruminal additives in further studies. The addition of MHEs used in this study had no significant negative effects on the ruminal fermentation characteristics. The in vitro ruminal methane production was reduced by addition of MHEs, and these MHEs dramatically suppressed the population of ruminal protozoa. For most of the ruminal additives including plants and plant secondary metabolites, their effects also depends on the diets as well. However, comprehensive in vivo studies with ruminants need to be conducted to evaluate the sustainability of MHEs supplementation to reduce the ruminal methane production and methanogenesis without adverse effects on the animal.

\section{CONFLICT OF INTEREST}

We certify that there is no conflict of interest with any financial organization regarding the material discussed in the manuscript.

\section{ACKNOWLEDGMENTS}

This work was carried out with the support of "Cooperative Research Program for Agriculture Science \& Technology Development (Project No. PJ011060)" Rural Development Administration, Republic of Korea. E. T. Kim was supported by Postdoctoral Fellowship Program of National Institute of Animal Science, Rural Development Administration, Republic of Korea.

\section{REFERENCES}

Barry, T. N., A. Thompson, and D. G. Armstrong. 1977. Rumen fermentation studies on two contrasting diets. 1. Some characteristics of the in vivo fermentation, with special reference to the composition of the gas phase, oxidation/reduction state and volatile fatty acid proportions. J. Agric. Sci. Camb. 89:183-195.

Carroll, E. J. and R. E. Hungate. 1955. Formate dissimilation and methane production in bovine rumen contents. Arch. Biochem.
56:525-536.

Denman, S. E. and C. S. McSweeney. 2006. Development of a real-time PCR assay for monitoring anaerobic fungal and cellulolytic bacterial populations within the rumen. FEMS Microbiol. Ecol. 58:572-582.

Denman, S. E., N. W. Tomkins, and C. S. McSweeney. 2007. Quantitation and diversity analysis of ruminal methanogenic populations in response to the antimethanogenic compound bromochloromethane. FEMS Microbiol. Ecol. 62:313-322.

Dubois, B., N. W. Tomkins, R. D. Kinley, M. Bai, S. Seymour, N. A. Paul, and R. de Nys. 2013. Effect of tropical algae as additives on rumen in vitro gas production and fermentation characteristics. Am. J. Plant Sci. 4:34-43.

Durmic, Z., P. J. Moate, R. Eckard, D. K. Revell, R. Williams, and P. E. Vercoe. 2014. In vitro screening of selected feed additives, plant essential oils and plant extracts for rumen methane mitigation. J. Sci. Food Agric. 94:1191-1196.

Ellis, J. L., E. Kebreab, N. E. Odongo, B. W. McBride, E. K. Okine, and J. France. 2007. Prediction of methane production from dairy and beef cattle. J. Dairy Sci. 90:3456-3467.

Eom, T. H., J. H. Kim, S. I. Lee, and J. G. Jeong. 2013. A herbalogical study on the plants of Iridaceae in Korea. Kor. J. Herbol. 28:85-93.

FAO. 2006. Livestock's long shadow. Environmental issues and options. Food and Agriculture Organization of the United Nations, Rome, Italy.

Hillman, K., D. Lloyd, and A. G. Williams. 1985. Use of a portable quadrupole mass spectrometer for the measurement of dissolved gas concentrations in ovine rumen liquor in situ. Curr. Microbiol. 12:335-339.

Hristov, A., M. Ivan, L. Neill, and T. McAllister. 2003. Evaluation of several potential bioactive agents for reducing protozoal activity in vitro. Anim. Feed Sci. Technol. 105:163-184.

Hungate, R. E. 1967. Hydrogen as an intermediate in the rumen fermentation. Arch. Mikrobiol. 59:158-164.

Janssen, P. H. 2010. Influence of hydrogen on rumen methane formation and fermentation balances through microbial growth kinetics and fermentation thermodynamics. Anim. Feed Sci. Technol. 160:1-22.

Johnson, K. A. and D. E. Johnson. 1995. Methane emissions from cattle. J. Anim. Sci. 73:2483-2492.

Kim, J. J., H. J. Lee, and S. T. Yee. 2012. Effect of Pueraria thunbergiana extracts on the activation of immune cells. J. Life Sci. 22:1107-1113.

Kim, S. J. and G. H. Kim. 2003. Identification for flavones in different parts of Cirsium japonicum. Prev. Nutr. Food Sci. 8:330-335.

Knapp, J. R., G. L. Laur, P. A. Vadas, W. P. Weiss, and J. M. Tricarico. 2014. Invited review: Enteric methane in dairy cattle production: Quantifying the opportunities and impact of reducing emissions. J. Dairy Sci. 97:3231-3261.

Koike, S. and Y. Kobayashi. 2001. Development and use of competitive PCR assays for the rumen cellulolytic bacteria: Fibrobacter succinogenes, Ruminococcus albus and Ruminococcus flavefaciens. FEMS Microbiol. Ecol. 204:361366.

Latham, M. J. and M. J. Wolin. 1977. Fermentation of cellulose by Ruminococcus flavefaciens in the presence and absence of Methanobacterium ruminantium. Appl. Environ. Microbiol. 
34:297-301.

Lee, H. H., S. Y. Kim, Y. M. Ko, J. S. Kim, and S. Y. Lee. 2009. Total polyphenol and flavonoid content and antioxidant activity on ethanol extracts of Arisaema amurense var. serratum Nakai. Tuber. In: Proceedings of the 2009 Spring Symposium of the Plant Resources Society of Korea. 179 p.

Makkar, H. P. S., M. Blümmel, and K. Becker. 1995. In vitro effects of and interactions between tannins and saponins and fate of tannins in the rumen. J. Sci. Food Agric. 69:481-493.

McDougall, E. I. 1948. Studies on ruminant saliva. 1. The composition and output of sheep's saliva. Biochem. J. 43:99109.

Minato, H. and T. Suto. 1978. Technique for fractionation of bacteria in rumen microbial ecosystem. II. Attachment of bacteria isolated from bovine rumen to cellulose powder in vitro and elution of bacteria attached therefrom. J. Gen. Appl. Microbiol. 24:1-16.

Mitsumori, M. and W. Sun. 2008. Control of rumen microbial fermentation for mitigating methane emissions from the rumen. Asian Australas. J. Anim. Sci. 21:144-154.

Ntaikou, I., H. N. Gavala, M. Kornaros, and G. Lyberatos. 2008. Hydrogen production from sugars and sweet sorghum biomass using Ruminococcus albus. Int. J. Hydrogen. Energy 33:11531163.

Oskoueian, E., N. Abdullah, and A. Oskoueian. 2013. Effects of flavonoids on rumen fermentation activity, methane production, and microbial population. BioMed Res. Int. Article ID 349129.
Patra, A. K. and J. Saxena. 2010. A new perspective on the use of plant secondary metabolites to inhibit methanogenesis in the rumen. Phytochemistry 71:1198-1222.

Patra, A. K. and Z. Yu. 2012. Effects of essential oils on methane production and fermentation by, and abundance and diversity of, rumen microbial populations. Appl. Environ. Microbiol. 78:4270-4280.

SAS Institute. 1996. SAS User Guide. Release 6.12 edition, SAS Inst. Inc. Cary, NC, USA.

Skillman, L. C., A. F. Toovey, A. J. Williams, and A. D. Wright. 2006. Development and validation of a real-time PCR method to quantify rumen protozoa and examination of variability between Entodinium populations in sheep offered a hay-based diet. Appl. Environ. Microbiol. 72:200-206.

Tan, H. Y., C. C. Sieo, N. Abdullah, J. B. Liang, X. D. Huang, and Y. W. Ho. 2011. Effects of condensed tannins from Leucaena on methane production, rumen fermentation and populations of methanogens and protozoa in vitro. Anim. Feed Sci. Technol. 169:185-193

Theodorou, M. K., B. A. Williams, M. S. Dhanoa, A. B. McAllan, and J. France. 1994. A simple gas production method using a pressure transducer to determine the fermentation kinetics of ruminant feeds. Anim. Feed Sci. Technol. 48:185-197.

Vogels, G. D., W. F. Hoppe, and C. K. Stumm. 1980. Association of methanogenic bacteria with rumen ciliates. Appl. Environ. Microbiol. 40:608-612. 